\title{
Rehabilitation Treatment In Dysarthria Caused By Stroke (Review)
}

\author{
Parvane Rahimifar ${ }^{1}$,M ajid Soltani ${ }^{2,3^{*}}$, Negin Moradi ${ }^{2,3}$ \\ ${ }^{1}$ MSc Speech Therapy, Musculoskeletal Rehabilitation Research Center, Ahvaz Jundishapur University Of M edical \\ Sciences, Ahvaz, Iran. \\ ${ }^{2}$ M usculoskeletal Rehabilitation Research Center. Ahvaz Jundishapur University Of M edical Sciences, Ahvaz ,Iran. \\ ${ }^{3}$ Dept. of Speech Therapy, Ahvaz Jundishapur University Of M edical Sciences , Ahvaz , Iran. \\ *Corresponding Author: Email: soltani-m@ajums.ac.ir
}

Speech is a unique, complex, dynamic motor activity through which we express thoughts and emotions and respond to and control our environment. Speech damaged due to neurological damage such as stroke. As a consequence of the associated neurological damage, stroke, approximately $20-30 \%$ of this population experience weakness, in-coordination or paralysis of the muscles required to produce speech, known as dysarthria. unfortunately dysarthria in stroke tends not to receive specific attention in published texts and reports, despite its frequency. while the speech is among the most powerful tools in communication and speech problems lead to defects in quality of life, So We investigated Dysarthria rehabilitation in stroke patients.

The Results showed that, the speech-language Pathologists (SLPs) are the professionals normally responsible for dysarthria intervention. Their interventions for individuals with dysarthria depend on the type and nature of the dysarthria, the underlying neuropathology, and the specific communication needs of the individual. SLPs interventions include behavioral or traditional therapy techniques and instrumental techniques, that can be improve speech, communication and quality of lifes.

Key words: Dysarthria, Speech disorder, Rehabilitation, Stroke

DOI: $10.7575 /$ aiac.abcmed.ca1.26

Published Date: February 2017

Peer-review is under responsibility of the 9th Iranian Stroke Congress.

Published by Australian International Academic Centre, Australia

This published work is open access under the CC BY license.

Available online at www.abcmed.aiac.org.au 